\title{
Cranial ultrasound assessment of gestational age in low birthweight infants
}

\author{
N P MURPHY, J RENNIE, AND R W I COOKE \\ Neonatal Intensive Care Unit, Liverpool Maternity Hospital, Liverpool
}

SUMmARY The anatomical features of the cerebral hemispheres of 97 infants were studied by ultrasonography. A scoring system was devised based on anatomical and ultrasound appearances and compared with gestational age calculated from the date of the mother's last period. There was a significant positive correlation between gestational age and ultrasound score. Cranial ultrasonography is an accurate and reproducible method of assessing gestational age in low birthweight infants.

There is a need for accurate method of assessment of gestational age in very low birthweight infants. Preterm infants with appropriate birthweights for their gestational ages present problems of management that are different from those of infants who are small for gestational age. ${ }^{1}$ Furthermore, the clinician requires an accurate baseline for follow up of growth and neurodevelopment. Existing methods of assessing gestational age are based on studies of infants of 32 weeks' gestation or more. ${ }^{1}$ These methods are often inaccurate ${ }^{2}$ or difficult to apply in the very low birthweight group.

Brain maturation based on necropsy appearances correlates well with gestational age according to the maternal menstrual history. From the 24th to the 34 th week of gestation there are important identifiable changes in the cerebral surface,$^{3-5}$ and principal sulci develop and alter in complexity each week. After 34 weeks, as the gyri increase in complexity, distinctive changes are less easy to identify. ${ }^{3}$

Real time ultrasound is a non-invasive method of studying the important changes in the neonatal brain. This study was undertaken to assess the use of ultrasonography in determining gestational age in very low birthweight infants.

\section{Patients and methods}

All infants studied had been admitted to the neonatal intensive care unit and their scans were carried out during the first 3 days of life. The mean (SD) gestational age of the study group was 29.7 (2.5) weeks, range 24-34 weeks, and the mean (SD) birthweight was 1260 (420) g, range 610-2100 g. There were 55 boys and 43 girls. Gestational age was based on the mother's menstrual history. ${ }^{6}$ Infants of mothers with irregular menstrual cycles or bleeding in early pregnancy were excluded. Also excluded were infants of mothers with prolonged rupture of membranes (longer than two weeks) or prolonged hypertension, or those who had been taking steroids for longer than two weeks, as these are associated with acceleration of neurological and pulmonary maturity in the fetus. ${ }^{7}$ Note was also taken of each antenatal ultrasound assessment of gestational age ${ }^{8}$ where these were in agreement with the mother's menstrual history and the fundal size.

Ultrasound scans were carried out through the anterior fontanelle using an ATL $850 \mathrm{~A}$ sector scanner with $5 \mathrm{mHz}$ transducers. Images were obtained in three planes, tangental, midsaggital, and coronal, and photographed with 'Polaroid' film to provide a permanent reproducible record.

The first appearance and increasing complexity of the principal sulci with increasing maturity in each place was noted (table). To standardise the assessment a scoring system was devised using diagrams based on anatomical and ultrasound appearances (fig 1). ${ }^{3457}$ The Polaroid prints were compared with the diagrams and scored by three independent observers skilled in the interpretation of neonatal cranial ultrasound scans but unaware of the clinical details of the patients.

\section{Results}

Ninety seven infants had ultrasound scans carried out during the first 3 days of life, and images in three planes (tangental, midsaggital and coronal) were produced on Polaroid prints of sufficient quality to 
Table Appearance and increasing complexity of the principal sulci noted in each plane with increasing maturity 47

\begin{tabular}{|c|c|c|}
\hline Midsaggital & Tangential & Coronal \\
\hline $\begin{array}{l}0 \text { Calcarine and posterior calcarine sulci } \\
\text { already present. Absent cingulate sulcus }\end{array}$ & $\begin{array}{l}0 \text { Smooth cerebral hemispheres. } \\
\text { Lateral sulcus wide open }\end{array}$ & $\begin{array}{l}0 \text { Wide open appearance of lateral } \\
\text { sulci }\end{array}$ \\
\hline $\begin{array}{l}1 \text { Calcarine and posterior calcarine sulci } \\
\text { more apparent. First appearance of } \\
\text { cingulate sulcus }\end{array}$ & $\begin{array}{l}1 \text { Central sulci may appear. } \\
\text { Lateral sulcus closing }\end{array}$ & $\begin{array}{l}1 \text { Early closure of lateral sulci } \\
\text { (apposition of parietal and } \\
\text { temporal lobes) }\end{array}$ \\
\hline $\begin{array}{l}2 \text { Cingulate sulcus easily visible, } \\
\text { straight and simple }\end{array}$ & $\begin{array}{l}2 \text { Central and posterior central sulci } \\
\text { visible. Lateral sulcus closed. } \\
\text { First appearance of superior } \\
\text { temporal sulcus }\end{array}$ & 2 Further closure of lateral sulci \\
\hline $\begin{array}{l}3 \text { Posterior calcarine and parieto-occipital } \\
\text { sulci more compressed. Cingulate } \\
\text { sulcus more tortuous and now } \\
\text { extending anteriorly }\end{array}$ & $\begin{array}{l}3 \text { Lateral sulcus more tortuous with } \\
\text { further closure. Superior temporal } \\
\text { sulcus more apparent, inferior } \\
\text { temporal sulcus now visible }\end{array}$ & 3 Lateral sulci now fully closed \\
\hline $\begin{array}{l}4 \text { Cingulate sulcus more tortuous now } \\
\text { extending posteriorly }\end{array}$ & $\begin{array}{l}4 \text { Inferior temporal sulcus more } \\
\text { apparent }\end{array}$ & $\begin{array}{l}4 \text { Lateral sulci now fully closed and } \\
\text { more tortuous with increase in size } \\
\text { of the parietal and temporal lobes }\end{array}$ \\
\hline $\begin{array}{l}5 \text { Further posterior extension of } \\
\text { cingulate sulcus. Further compression } \\
\text { of parieto-occipital and posterior } \\
\text { calcarine sulci }\end{array}$ & 5 Superior frontal sulcus now visible & \\
\hline
\end{tabular}

Scoring system: $0=24-25$ weeks, $5=34+$ weeks.
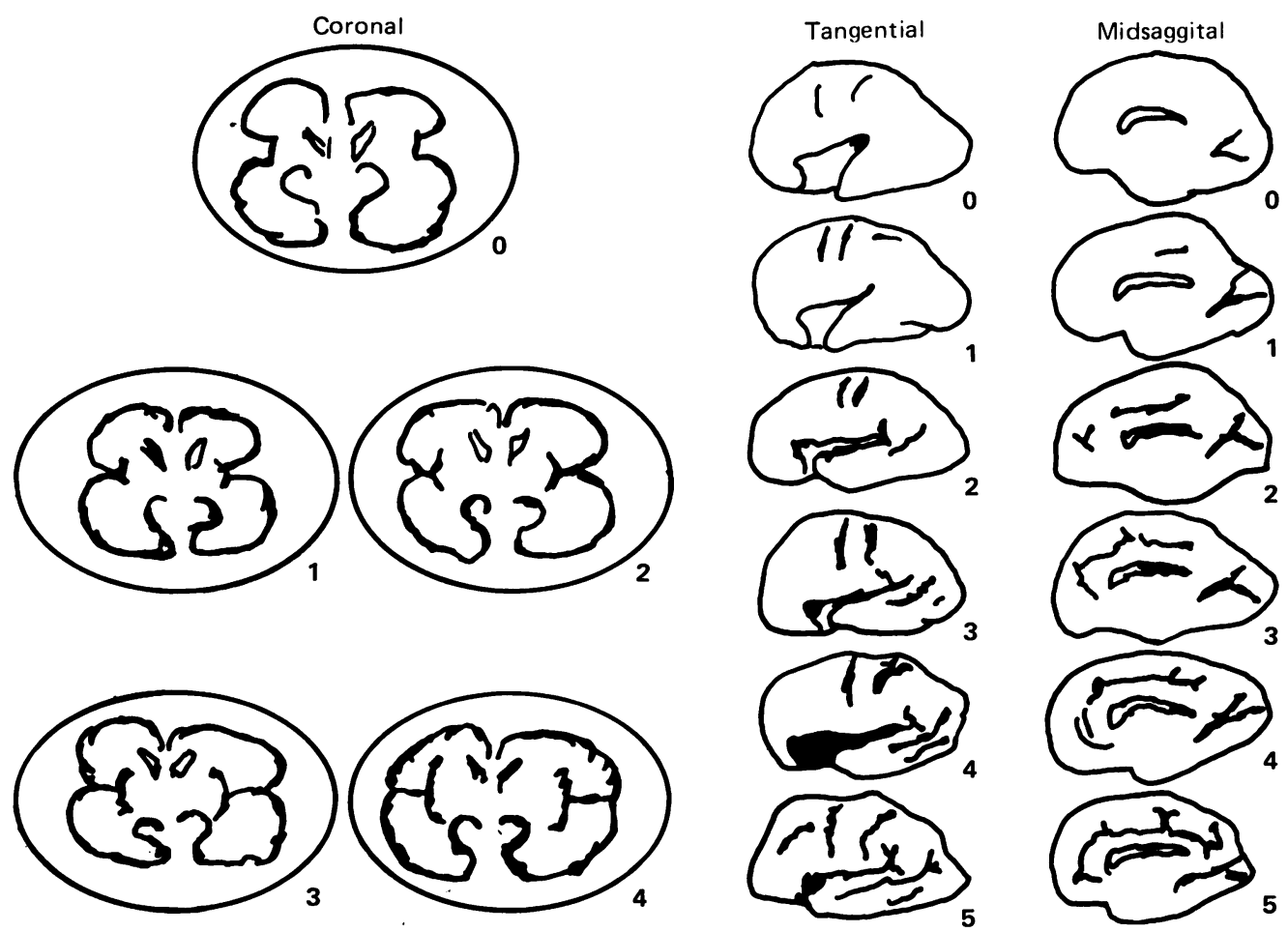

Fig 1 Anatomical diagrams showing the increasing complexity of the principal sulci noted in each plane with increasing maturity. ${ }^{347}$ 
permit independent assessment. The sulci that were most consistently identified with distinctive changes as maturity advanced were the precentral and postcentral and the superior and inferior temporal sulci in the tangental plane, the cingulate sulcus in the midsaggital plane, and the closure and infolding of the lateral sulcus in the coronal plane (fig 2).

The mean gestational age was 30 weeks (range 24-34). Regression lines were calculated for the scores on gestational age for each of the three observers. There was a significant positive correlation between gestational age and increasing ultrasound score for each observer $(r=0 \cdot 76-0 \cdot 84$, $\mathrm{p}<0.001)$. One way analysis of variance (KruskalWallace) among observers showed a significant association of the scores for the same subjects $(p<0 \cdot 01)$. Fig 3 shows the same regression line for the median scores for the three observers with the $95 \%$ confidence intervals $(r=0 \cdot 84)$. After 34 weeks' gestation weekly anatomical changes were less distinct. The study was not therefore extended
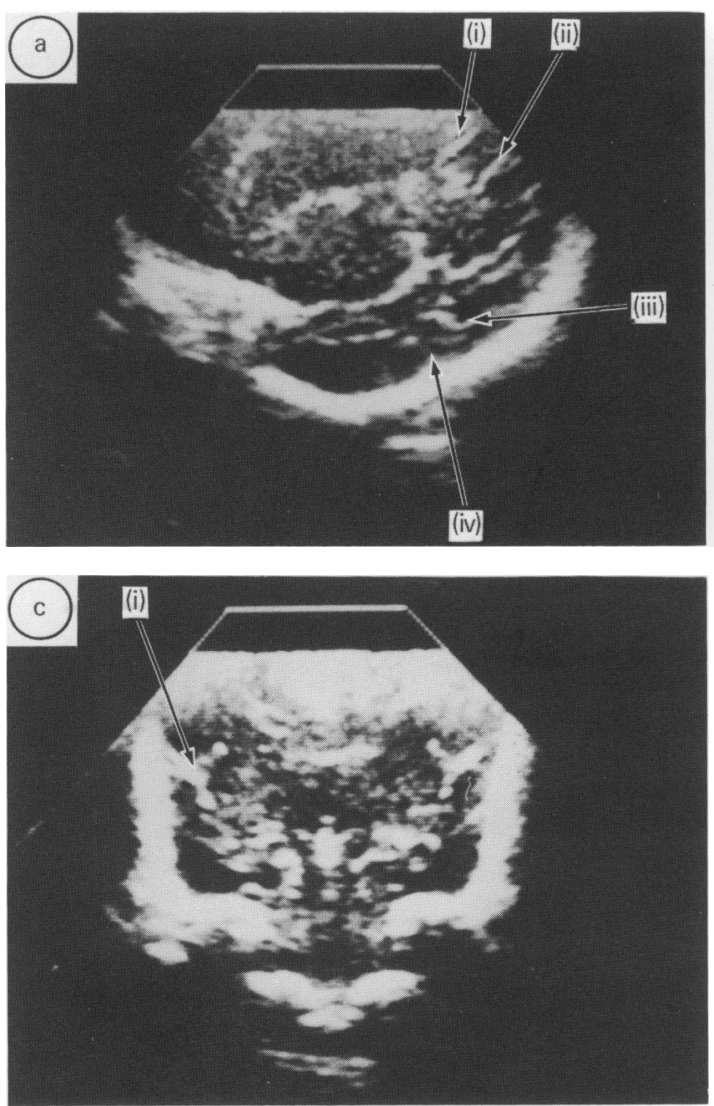

beyond this point, as methods of assessing gestational age of 34 weeks or more are well established.

\section{Discussion}

Many methods have been introduced for assessment of gestational age in newborn infants. ${ }^{1}$ All the methods have been based on studies of infants of 32 weeks' gestation or more. As standards of neonatal intensive care have advanced during the past decade, large numbers of low birthweight infants with gestational ages ranging from 24-32 weeks have survived. Because of the many clinical problems that these infants have, the application of the accepted scoring methods is difficult and often inaccurate. ${ }^{2}$ These difficulties and inaccuracies prompted this study. Infants who require mechanical ventilation do not tolerate handling and so the use of ultrasonography, which can be carried out with minimal disturbance, is a reasonable alternative.

The principal sulci may be identified without great

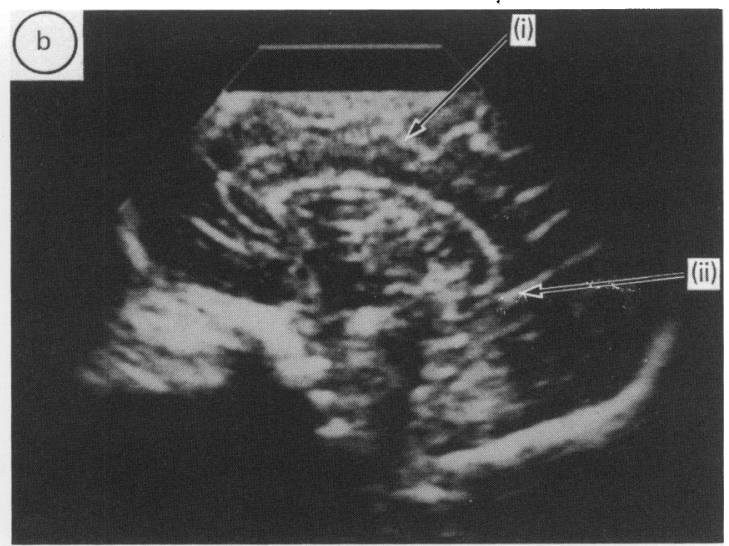

Fig 2 a (i) Precentral sulcus, (ii) postcentral sulcus, (iii) superior temporal sulcus, (iv) inferior temporal sulcus. b (i) Cingulate sulcus, (ii) postcalcarine sulcus. $c$ (i) Lateral sulcus. 


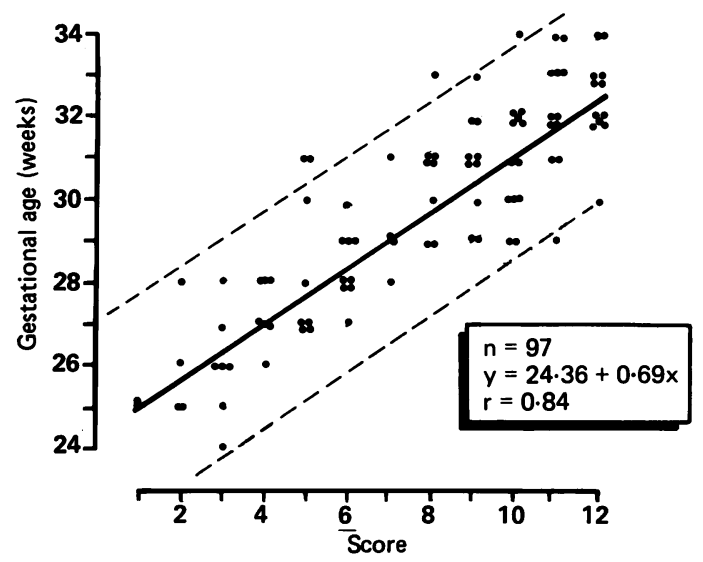

Fig 3 Regression line of cumulative score and gestational age.

difficulty in three planes. Some practical difficulty was encountered when the anterior fontanelle was small, but this was not common and could be overcome by repeating the scan. The use of Polaroid prints permitted independent assessment and scoring by three observers. The prints were retained as a permanent reproducible record. The scoring system showed a good correlation with the mother's menstrual history, with a linear increase in gestational age associated with increasing complexity of the brain surface marking on ultrasonography. There was, however, a wide standard deviation. The addition of more variables and perhaps the com- bination of ultrasonography and superficial criteria could well produce an accurate, non-invasive, and reproducible method of assessing gestational age in low birth weight infants. In addition, this technique could be used to study the effects of perinatal factors such as intrauterine growth retardation on the rate of brain maturation.

The authors wish to thank Dr MEI Morgan for her help in reading and interpreting scans. We thank Mr Ken Walters for providing the illustrations and Mrs Megan Bird for typing the manuscript.

\section{References}

1 Dubowitz LMS, Dubowitz V. Gestational age of the newborn. Reading, Massachusetts: Addison-Wesley Publishing Company, 1977.

2 Spinnato JA, Sibai BM, Shaver DC, Anderson GD. Inaccuracy of Dubowitz gestational age in low birth weight infants. Obstet Gynecol 1984;63:491-5.

3 Dorovini-Zis K, Dolman CL. Gestational development of brain. Archives of Pathological and Laboratory Medicine 1977; 101:192-5.

4 Chi JG, Dooling EC, Gilles FH. Gyral development of the human brain. Ann Neurol 1977;i:86-93.

5 Minkowski A, Larroche JC, Vigrand J, et al. The development of the central nervous system in early life. Philadelphia: WB Saunders, 1966:257-68.

6 Stewart HL Jr. Duration of pregnancy and postmaturity. JAMA 1952;148:1079-83.

${ }^{7}$ Hamid AH. Fetal cerebral maturation in hypertensive disorders of pregnancy. Obstet Gynecol 1984;63:214-9.

8 Campbell $\mathrm{S}$. The prediction of fetal maturity by ultrasound measurement of the biparietal diameter. Journal of Obstetrics and Gynaecology of the British Commonwealth 1969;76:603-9.

Correspondence to Dr NP Murphy, Maternity Wing, Countess of Chester Hospital, Liverpool Road, Chester CH2 1BQ.

Accepted 29 July 1988 